\title{
GENETIC POLYMORPHISMS IN PATIENTS WITH SYSTEMIC LUPUS ERYTHEMATOSUS AND JACCOUD ARTHROPATHY: A PILOT STUDY
}

Anna Paula Mota Duque Sousa ${ }^{1,2}$, Giselle Calasans de Souza Costa ${ }^{2,3}$, Gustavo Nunes de Oliveira Costa ${ }^{2}$, Lúcio Macedo Barbosa ${ }^{3}$, Maria Fernanda Rios Grassi ${ }^{3}$, Maria Eduarda Haerdy Monteiro², Mitermayer Galvão dos Reis ${ }^{3}$, Maurício Lima Barreto ${ }^{3}$, Ana Luisa Pedreira ${ }^{1}$, Daniel Sá Ribeiro ${ }^{1}$, Carolina Freitas Lins ${ }^{1}$, Verena Galvão ${ }^{1}$, Willer Gonçalves Dourado Santos ${ }^{1}$, Viviane Machicado ${ }^{1,2}$, Emanuela Pimenta da Fonseca ${ }^{1}$, Carla Baleeiro Rodrigues Silva ${ }^{1}$, Mittermayer Barreto Santiago ${ }^{1,2,4, *}$

1.Escola Bahiana de Medicina e Saúde Pública, Salvador (BA), Brazil. 2.Universidade Federal da Bahia, Salvador (BA), Brazil. 3.Fundação Oswaldo Cruz, Salvador (BA), Brazil. 4.Serviços Especializados em Reumatologia da Bahia, Salvador (BA), Brazil.

*Corresponding author: mitter.santiago@serdabahia.com.br

\section{BACKGROUND}

Jaccoud arthropathy $(\mathrm{JA})$ is a nonerosive and deforming arthropathy currently experienced more frequently by patients with systemic lupus erythematosus (SLE). Although genetic polymorphisms are associated with SLE development, the association between genetic polymorphisms and JA has not been studied to date. The main objective of this study was to evaluate an association between HLA, STAT4, IRF5, and BLK polymorphisms and the presence of JA in Brazilian individuals with SLE.

\section{MATERIALS AND METHODS}

Patients were selected from a cohort of individuals with SLE followed at two rheumatology reference centers in Salvador, Bahia, Brazil. The JA diagnosis was based on clinical and radiological criteria. The participants were genotyped for rs9271100, rs7574865, rs10488631, and rs13277113 polymorphisms in the HLA, STAT4, IRF5, and BLK genes, respectively, using real-time polymerase chain reaction. The presence of JA was correlated with allele frequencies, and clinical and laboratory data.

\section{RESULTS}

One hundred forty-four individuals with SLE (38 with JA and 106 with SLE without JA) were studied. The mean age of the patients was $45 \pm 12$ years; the majority were women and had brown skin. Patients with JA had a longer disease duration than patients without JA. Serositis and neuropsychiatric manifestations were more frequent in the JA population. The A allele of rs13277113 in the BLK gene was associated with the presence of JA.

\section{CONCLUSION}

The rs13277113 polymorphism in the BLK gene was found to be a possible genetic risk for JA development. However, further studies in larger populations should be performed to confirm this finding. 